\title{
Tethering System Design for Dante II
}

\author{
Murali Krishna, John Bares, Ed Mutschler \\ The Robotics Institute \\ Carnegie Mellon University \\ Pittsburgh, PA - 15213, USA
}

\section{Introduction}

Over the last decade, mobile robot systems have demonstrated the ability to operate in severe environments, and perform hazardous tasks, and a number of these tasks require tethered robot systems. Tethered robotic systems have been used for asbestos removal [2], pipe inspection [3] and tank inspection [4], to name a few. Non-robotic tethered systems include manually operated logging machines on steep slopes with a steel tether for support, high-altitude weather monitoring systems with a tether to anchor the weather balloon and provide power and communication to the balloon, and underwater exploration.

Tethering systems typically consist of the tether (or umbilical), and components that stack the tether and manage the payout and reeling of the tether ${ }^{1}$. In addition to support, the tether can act as a conduit for any subset of the following -

- Power

- Data communication between remote computer or human controllers and the tethered system

- Gases, such as oxygen supplied to a submersible from a surface ship

- Fluids, such as hydraulic fluid or cleaning fluid for inspection and repair systems

- Other materials, such as debris from a vacuuming robot.

The need for tethering systems on mobile robots can be seen in applications such as removal of large contaminated structures ([6]), which have very high power demands. Although battery technology has made great advances recently, robots with high power demands still require external power supply through a tether. For robots working in enclosed spaces (e.g. pipes [3]) hard-wired communication lines are the only means of guaranteed communication with the robot. The tether may also serve as a means of robot deployment (e.g. a robot lowered through an opening at the top of an oil storage tank [4]), and could be used for robot retrieval in case of failure.

The area of tethering system design has received little attention in the literature. To the best of our knowledge no paper has examined tethering system design, especially for mobile robots, and there exists a need to understand it.

Dante II is a tethered mobile robot designed for volcano exploration. It was a very challenging case-study for tethering system design and encountered issues never before addressed in any application since it was the first in this unique class of exploring robots. This paper describes the issues faced in the

\footnotetext{
${ }^{1}$ There exist unmanned air vehicles that unreel tether as they proceed, but do not have the ability to reel the tether back in.
}

design of the tethering system of the Dante II robot, and the approach used to address these issues.

\section{Description of the Dante II Rappelling System}

Dante II is an eight-legged rappelling robot (Fig 1) that uses a tether to support itself on steep terrain, just as a mountaineer uses a climbing rope. The tether is connected to a generator and satellite communication station located at the volcano's rim. The satellite station relays data to and from remotely located operators.

Dante II's eight pantographic legs are organized as two groups of four - an inner frame and an outer frame. The two frames can translate and rotate with respect to each other. To walk, the four legs in the inner frame lift simultaneously. This is followed by translation of the inner frame with respect to the outer frame. At the end of this frame advance the four legs are placed down. The outer set of four legs is then lifted, at which point the inner legs are supporting the robot. The outer frame then advances, followed by placement of the four outer legs. Each of the legs can be individually raised to adjust to terrain irregularities. For each such walking cycle Dante II advances $1.1 \mathrm{~m}$. Turning is accomplished by raising one set of legs (inner or the outer frame), rotating the free frame with respect to the supporting frame, and placing the free frame down. This cycle is repeated a number of times to execute large rotations. For more details on the walker configuration see [1].

An onboard tethering system manages the $300 \mathrm{~m}$ of tether wrapped on a winch drum (Fig 1). The robot coordinates tether payout with leg motion to maintain an appropriate tether tension during the entire walking cycle. This is especially important while negotiating transitions in the terrain slope. The tether tension stabilizes the robot on steep slopes by counter-acting the moment that causes the robot to tip down the slope (Fig 2). The tether tension force also helps to increase the load on the uphill legs, and thus equalize the loads on all the legs. ${ }^{2}$

Dante II was extensively tested before and during a seven day exploration mission in Mt. Spurr, an active volcano $140 \mathrm{~km}$ west of Anchorage, Alaska. The robot was controlled by operators in Anchorage during the seven day mission. While climbing out of the volcano after successfully completing its mission, Dante fell on its side when attempting to cross extremely challenging terrain. The fall was partly caused by the unfavorable tether angle with respect to the robot. Since the robot was incapable of self righting, it was airlifted out of the volcano.

\footnotetext{
${ }^{2}$ The tether can contribute to destabilizing the robot if the tether angle $\phi$ is opposite to that in Fig 2
} 




Fig. 1. Dante II at a field test

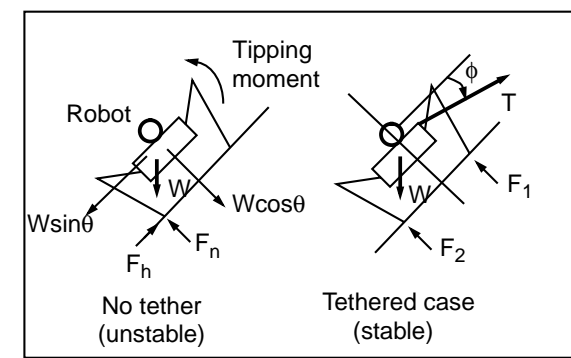

Fig. 2. The tether stabilizes the robot and equalizes leg loads.

\section{Issues in Tethering System Design}

We now discuss some of the issues involved in the Dante II tethering system design. The functional requirements of the tether are listed below, followed by the issues in the design.

\section{Tether functional requirements}

The tether for Dante II provides power to the robot, communication between the robot and the operators, and support on steep slopes.

The worst case static loading for the tether is when the robot is on a vertical slope as shown in Fig 3, when the tether supports the entire weight of the robot $(7700 \mathrm{~N})$. However certain dynamic events can increase peak tether load. For instance, if the tether pulls free of a snag, the robot could undergo a slight free fall resulting in a dynamic pull on the tether. The peak force can vary depending on the axial stiffness, length of free tether, and duration of fall.

Points of frictional terrain contact increase effective tether stiffness - shorter unsupported tether spans between the robot and the nearest terrain contact result in higher tether axial stiffness. For Dante II, a free fall of $0.5 \mathrm{~m}$ with an unsupported tether span of $15 \mathrm{~m}$, was judged to be a realistic worst case. Assuming that a $15 \mathrm{~m}$ span of the tether has a stiffness of 30000
$\mathrm{N} / \mathrm{m}^{3}$, this worst case results in a peak tension of $13600 \mathrm{~N}$.

In addition to tensile loading, the tether can also be subjected to sharp bends when draped over rocks or obstacles, as shown in Fig 3. Sharp bends cause stress concentrations which may adversely affect the mechanical and electrical performance of the tether. A worst case bend radius of $7 \mathrm{~mm}(0.25$ in.) was used as a realistic representation of a sharp rock edge.

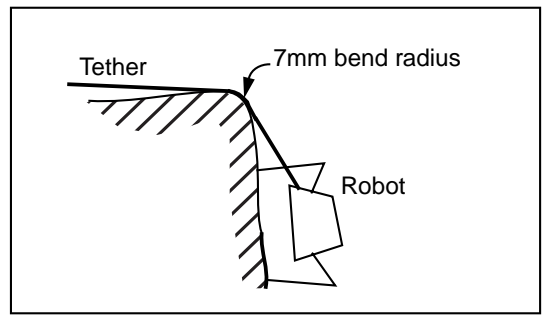

Fig. 3. Severe tether loading condition

Minimizing body weight is a key objective for a walking robot as the leg actuators must carry the body. Even a small decrease in tether diameter (or unit weight) would translate to a substantial decrease in total tether volume (or weight) due to the large amount of tether carried onboard DanteII.

TABLE 1: Summary of tether requirements

\begin{tabular}{|c|c|}
\hline Length & $300 \mathrm{~m}$ \\
\hline Unit weight & $\begin{array}{l}\text { Not to exceed } 0.3 \mathrm{~kg} / \mathrm{m} \text { (Final unit weight } \\
\text { was } 0.186 \mathrm{~kg} / \mathrm{m} \text { ) }\end{array}$ \\
\hline Max. static load & $7700 \mathrm{~N}$ \\
\hline Peak dynamic load & $13600 \mathrm{~N}$ \\
\hline $\begin{array}{l}\text { Min. bend radius ( } \text { Incl. } \\
\text { angle }<=90^{\circ} \text { ) }\end{array}$ & $\begin{array}{l}7 \mathrm{~mm} \text { (Tether required to function when } \\
\text { bent with max. tension load) }\end{array}$ \\
\hline Conductors in tether & $\begin{array}{l}\text { Communication path for } 2 \text { video channels } \\
(384 \mathrm{~Kb} / \mathrm{s} \text { each }), 1 \text { ethernet }(192 \mathrm{~Kb} / \mathrm{s}) \text {, } \\
\text { and } 4 \text { serial channels. }\end{array}$ \\
\hline & $\begin{array}{l}\text { Three 18AWG conductors for } 3 \mathrm{KW} \text { sin- } \\
\text { gle-phase AC@ } 1000 \mathrm{~V}\end{array}$ \\
\hline Temperature range & $-40^{\circ} \mathrm{C}$ to $100^{\circ} \mathrm{C}$ \\
\hline Environment & $\begin{array}{l}\text { Acidic steam with } \mathrm{HF}, \mathrm{HCl} \text { and } \mathrm{H}_{2} \mathrm{SO}_{4} \\
\text { acids. Worst case } \mathrm{pH} \text { of } 2 \text {. }\end{array}$ \\
\hline Min. life of tether & 500 hrs. \\
\hline Abrasion resistance & $\begin{array}{l}\text { Few tens of abrasive cycles over volcanic } \\
\text { rocks, at } 7700 \mathrm{~N} \text { of tension. }\end{array}$ \\
\hline
\end{tabular}

\section{A. Tether issues}

Tether constructions with an inner core of conductors surrounded by an outer layer of strength material (which bears most of the load) are widely used for undersea communication cables, where they are routinely subjected to high tensile loads of tens of thousands of Newtons during installation on the sea floor. Kevlar ([7]) is quite commonly used in such applications.

The authors are not aware of research studying the performance of aramid fiber tethers subjected to small radius bends.

\footnotetext{
${ }^{3}$ This corresponds to the stiffness of a braided Kevlar rope with a soft core. and a break strength of $44500 \mathrm{~N} / 10000 \mathrm{lbs}$.
} 
The most similar study identified looked at the performance of umbilicals (with/without steel armoring) under tension when cycled for hundreds of cycles over small diameter sheaves ([8]). Under high-tension small-radius bends, the performance of aramid fiber tethers is very different from that of tethers using steel wires as the strength member.

Since DanteII's tether presented new requirements for which no data was available, a prototype-and-test cycle for tether development was adopted.

\section{B. Tether-robot interaction}

The tether supports the robot on steep slopes and applies large external forces on the robot. Since the walking cycle for Dante II is a quasi-equilibrium process (i.e. all the states in the walking cycle are statically stable), a static force analysis was used to analyze robot stability, and determine criteria for a good winch configuration.

The effect of tether tension on robot stability was examined in three planes - X-Y, Y-Z, X-Z - illustrated in Fig 4-6. In the $\mathrm{X}-\mathrm{Y}$ and $\mathrm{Y}-\mathrm{Z}$ planes, undesirable moments $-\mathrm{T}_{\mathrm{X}}{ }^{*} \mathrm{r}$ and $\mathrm{T}_{\mathrm{Z}}{ }^{*} \mathrm{r}$ respectively - can be minimized by minimizing the distance between the tether exit and the center of the robot. Thus ideally, the winch, which contributes significantly to the overall robot weight, and tether exit should be located close to the center of the robot.

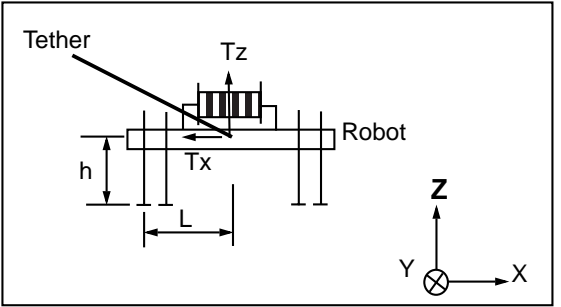

Fig. 4. Effects in the $X-Z$ plane (Rear view)

(Gravitational loads and foot forces not shown)

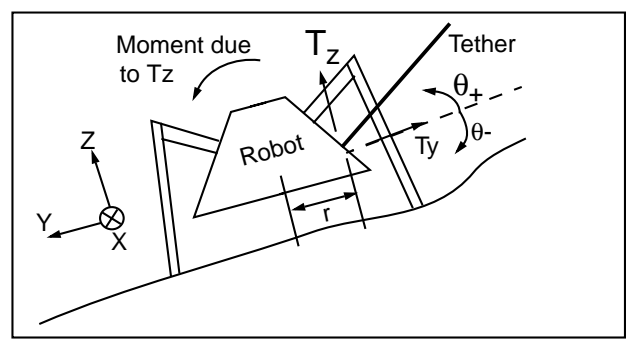

Fig. 5. Effects in the Y-Z plane (Side View)

(Gravitational and foot forces not shown)

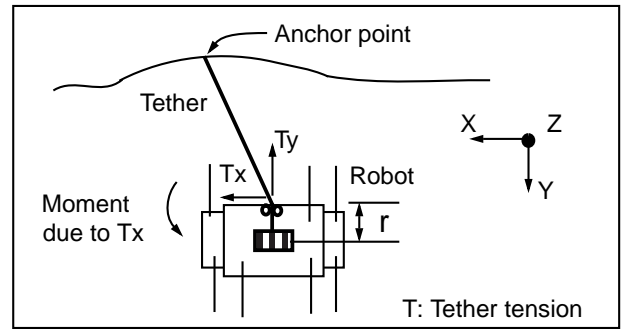

Fig. 6. Moment induced by deviation from the fall line (Top view) (Gravitational loads and foot forces not shown)
It should be noted that the various moments due to tether exit forces are not independent of each other, and in some cases may sum, possibly resulting in robot tip over.

\section{Tether stiffness effects}

Although a stiff tether can apply large forces on the robot making robot control very difficult, the tether bending stiffness is quite commonly ignored during the design phase of robot tethers ${ }^{4}$. (In marine applications, this problem is avoided by having neutrally buoyant tethers)

Accounting for tether flexibility during the design phase is problematic due to the long lead times and high cost of small test samples, and the difficulty in theoretically predicting the flexibility ${ }^{5}$. One way of tackling the problem is by experimenting with available tether samples of similar construction.

\section{Winch functional requirements}

The winch system consists of the winch drum, and tether cable management devices. When walking on steep slopes, the winch motion is used to control tether payout, which in turn controls the tether tension.

\section{TABLE 2: Summary of winch requirements}

\begin{tabular}{|l|l|}
\hline Max. operating tether tension & $7700 \mathrm{~N}$ \\
Peak holding tension & $13600 \mathrm{~N}$ \\
Total length of tether & $300 \mathrm{~m}$ \\
Peak winch drum speed & $3.5 \mathrm{rpm}$ (Wind tether faster than \\
walking speed) \\
To be determined from tether devel- \\
Diameter of tether & $-40^{\circ} \mathrm{C}$ to $100^{\circ} \mathrm{C}$ \\
& $\mathrm{Acidic}^{\circ}$ steam with $\mathrm{HF}, \mathrm{HCl}$ and \\
Temperature range & $\mathrm{H}_{2} \mathrm{SO} \mathrm{O}_{4}$ acids with pH=2 (min). \\
Environment & Active when powered off \\
Brake & $55 \mathrm{kgs} .(125 \mathrm{lbs})$. \\
Desired weight (without tether) & $45 \mathrm{~N}(10 \mathrm{lbs}$.) \\
Accuracy of tension sensing & 4
\end{tabular}

\section{Tether stacking}

When tether on the winch drum is subjected to high tension loads, tether stacking requires greater attention due to a phenomenon known as "knifing". Knifing occurs when the lower layers of tether on the winch drum are wound at low tension and the outer layer is subjected to high tension, causing the tether in the outer layer to knife its way to the bottom of the stack by forcing itself between the relatively loose wraps on each layer below. Knifing can cause tether damage and can also make subsequent payout extremely difficult. It can usually be avoided by winding the tether on the drum at a tenth of the maximum expected tension. In addition, for high tension applications, stacking on the drum should be uniform. Non-uniform

\footnotetext{
${ }^{4}$ We are aware of atleast one application [5] where, the tether was found to be very stiff and inflexible after it was manufactured, which necessitated some tether management system redesign.

${ }^{5}$ For instance, the extrusion pressure can greatly affect tether flexibility for tethers with extruded jackets, and the relationship is not easy to predict.
} 
tether stacking, while mechanically simple, can lead to gaps between wraps in a layer, causing the tether on the upper layer to knife.

Tether knifing is strongly related to the friction coefficient of the jacket - a tether with a lower friction coefficient has a higher chance of knifing.

\section{E. Powered fairlead}

When paying out tether at low tension, the absence of a force pulling the tether off the drum can lead to slack tether accumulating between the drum and the fairlead (or feed pulley). The drum and fairlead are indicated in Fig 11.

A powered fairlead can help solve the problem of low tension winding by an arrangement where the tether passes through a set of pinch rollers (the fairlead) with the rollers continuously trying to pull the tether off the drum. Since the fairlead must pinch the tether to generate tension, the tether jacket must be capable of transferring the load to the inner strength member, and if not bonded firmly to the core can be damaged by the pinching action 6 .

For DanteII, the tether had to pass through two sets of pulleys before exiting the robot. This, coupled with the high tether flexibility, kept the tether on the drum taut even when the free end of the tether was slack. A powered fairlead ${ }^{7}$ was therefore not used for DanteII.

\section{F. Tension Sensing}

The rappelling mode of operation used by Dante II uses active tether tension control for stabilization on steep slopes. Active tension control is especially required during slope transitions where the tether tension required to keep the robot stable changes rapidly. It was therefore very important that the tension sensing scheme be extremely reliable ${ }^{8}$. The tension sensing scheme for Dante II is described in Sec V.

\section{Tether development cycle}

As described in Sec A, due to lack of information on the performance of composite tethers subjected to high tension bending we decided to use a prototype-test design cycle.

We received two test samples with similar constructions but with different jacket and conductor insulation materials, resulting in two very different diameters of $11.5 \mathrm{~mm}\left(0.45^{\prime \prime}\right)$ and $18 \mathrm{~mm}(0.70$ "). The larger diameter sample was found to be too inflexible for our use, and tests were only conducted on the smaller sample.

The initial tether tested is shown in Fig 7. The same construction was also used for the final tether though some changes were made to the jacket based on the results of the testing program. The tether contains an inner core of copper conductors.

\footnotetext{
${ }^{6}$ In some cases the jacket strength can be increased by weaving a braid of the strength member in the jacket.

${ }^{7}$ The winch was designed to allow the addition of motors to power the fairlead, since the tether development effort concluded after the winch design was finalized

${ }^{8}$ Since the tether is reeled out during the walking cycle, it cannot be read directly off of the tether.
}

A $0.1 \mathrm{~mm}$ thick sheath of low-friction Gore-Tex ${ }^{9}$, was used to wrap the conductor core. This was then surrounded by a layer of Technora (a Kevlar ${ }^{10}$ variant) which acts as the strength member and bears most of the tensile load applied to the tether A hytrel jacket encloses and protects the insides of the tether.

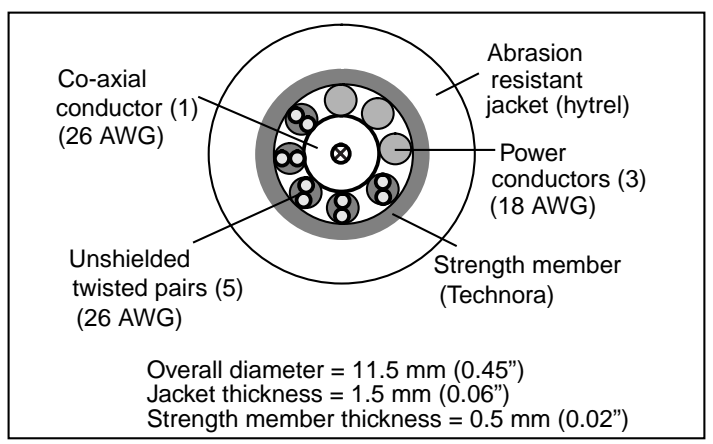

Fig. 7. Cross-section of Dante II's tether

\section{A. Tether tests}

Tests conducted on the smaller diameter sample are briefly described below in the order in which they were performed. For all the tests, power was supplied through the wires in the tether, ethernet signal was transmitted through the twisted pairs, and video signal was transmitted through the co-axial cable. Unless otherwise mentioned, these signals were monitored during all tests.

\section{Simple tension pull:}

This test consisted of securing the test sample at both ends and slowly increasing tension while monitoring signal throughput. No adverse effects were observed.

\section{Winding on winch drum under tension:}

This was carried out to investigate possibilities of

(a) tether performance degradation due to stacking on the drum

(b) tether knifing (described in Sec D)

The tether was wound on a $200 \mathrm{~mm}$ diameter winch drum with $1300 \mathrm{~N}$ of tether tension (10\% of the maximum expected tether tension). Once the tether had formed a bottom layer on the drum and had started forming the second layer, tether tension was raised to $7700 \mathrm{~N}$. No change in signal throughput or knifing was observed.

\section{Tension-coupled-with-bend}

This test investigated the effect of bending the tether over a $7 \mathrm{~mm}$ radius edge with an included angle of $90^{\circ}$, and with $7700 \mathrm{~N}$ of tether tension (Fig 8). It was speculated that the bending might cause the layer of strength fiber in the tether to redistribute itself at the bend cross-section, resulting in tensile loading of the conductor core.

During the test, the tether was placed over the radius block, tension increased to $7700 \mathrm{~N}$, then decreased to zero using the winch. Between cycles, the tether was tensioned to $7700 \mathrm{~N}$ in a straight position (without inducing any bend). Although some shifting of the Technora strength member was observed it was not severe enough to affect conductor performance.

\footnotetext{
${ }^{9}$ Gore-Tex is a registered trademark of W.L.Gore and Associates.

${ }^{10}$ Kevlar is a registered trademark of Du Pont.
} 
The behavior of the tether jacket during this test pointed to a potential problem. When bent, the jacket on the underside of the bend would buckle and crumple. This was alleviated by increasing the jacket thickness.

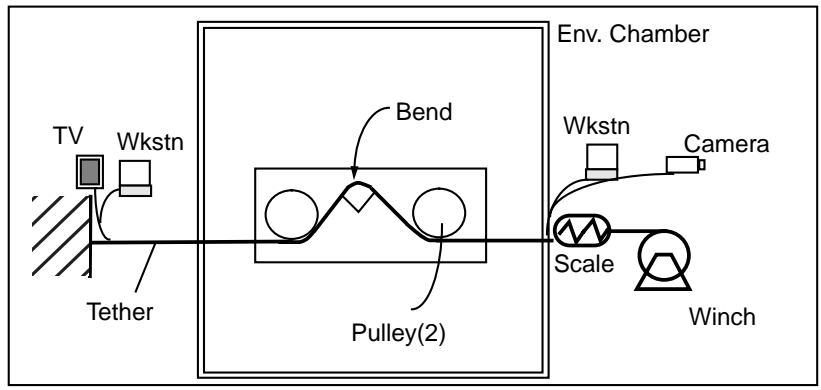

Fig. 8. Test setup to test bending-under-tension (Side view)

\section{Tension-coupled-with-bend at $-40^{\circ} \mathrm{C}$}

To investigate the effect of low temperatures on the jacket, the above test was repeated at $-40^{\circ} \mathrm{C}$, by housing the setup in an environmental chamber (Fig 8). The cold did not seem to significantly affect the test result.

\section{Flex-testing in cold:}

This is a test recommended for hose and hose assemblies used in low temperature transmission oil systems, as per the SAE J1019 JUN 90 standard [9]. A similar test was devised to ensure satisfactory jacket performance under low temperature bending. A sample of the tether was frozen for $8 \mathrm{hrs}$ at $-40 \mathrm{C}$ in a straight position, rapidly bent $90^{\circ}$ over a $25 \mathrm{~mm}$ radius edge (twice the tether diameter), and then inspected. No cracks or surface distortions were observed even after multiple flexing operations.

\section{Dynamic load test:}

This investigated the effect of a dynamic load on the test sample. As mentioned in Sec III, in the worst case the robot could slip on a slope, inducing a dynamic shock load on the tether when bent on a rock or ledge.

To simulate the worst case, the arrangement shown in Fig 9 was used. Throughput of signal was not monitored during this test which involved generating $13600 \mathrm{~N}$ of peak tension ${ }^{11}$ in the cable while bent over a $7 \mathrm{~mm}$ radius fixture. Although the specified worst case condition called for a $90^{\circ}$ bend, the test fixture used a $180^{\circ}$ bend for ease of implementation. The conductors were found to be functioning normally after the test.

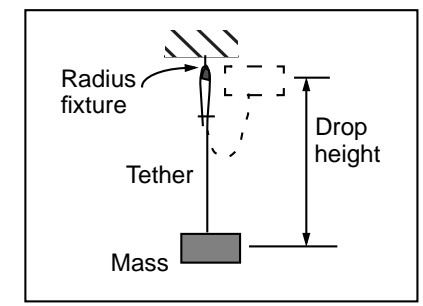

Fig. 9. Test setup for dynamic load tests

\section{Abrasion testing}

In this test, the test sample was abraded on a volcanic rock

\footnotetext{
${ }^{11}$ Using a tether stiffness of $30000 \mathrm{~N} / \mathrm{m}$, we required a $45 \mathrm{~kg}$ mass dropped through $4.2 \mathrm{~m}$ to generate the required peak tension.
}

sample as shown in Fig 10, to determine the susceptibility of the jacket to abrasion. The turnbuckle (tensioning device) was used to tension the tether to $7700 \mathrm{~N}$. The arm was then rocked back and forth to abrade the tether on the rock sample. The dimensions were adjusted to have a wrap angle of $90^{\circ}$.

It was observed that although sharp edges (edge radius $<1.5$ $\mathrm{mm}$ ) on the rock surface tore the jacket quite easily (within 20 cycles), no damage to the core was observed even at the end of 100 cycles. The test was performed using two faces of the rock sample with different roughness.

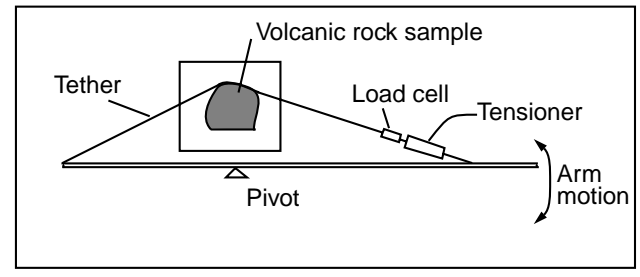

Fig. 10. Abrasion test setup (Top View)

This completes the battery of tether performance tests. Based on observations made during the abrasion and bending tests, the jacket thickness of the tether was increased by $0.25 \mathrm{~mm}$ (0.01 in.). This increased the bending stiffness of the tether, but solved the problem of the jacket buckling. The jacket extrusion pressure was also increased resulting in a tighter jacket fit.

\section{Winch system design}

The winch system is shown in Fig 11. The motion of the level-wind is synchronized with the drum rotation through a chain drive, to ensure that the level-wind advances by a single tether diameter for every drum rotation. A slip-ring housed in the winch drum transfers power and data from the rotating end of the tether to the robot electronics mounted on the body. A fail safe brake attached to the motor shaft maintains tension even in case of power failure. Tether payout is monitored using a potentiometer.

\section{TABLE 3: Winch description}

\begin{tabular}{|l|l|}
\hline Drive & Brushless DC motor \\
Gear box & $178: 1$ \\
Chain drive & $7: 1$ \\
Weight (no tether) & $110 \mathrm{~kg}(250 \mathrm{lbs})$ \\
Drum diameter & $324 \mathrm{~mm}(12.75 \mathrm{in})$. \\
Overall dimensions & $1.0 \mathrm{~m}$ X $0.75 \mathrm{~m} \mathrm{X} 0.75 \mathrm{~m}$ \\
Max drum speed & $3.5 \mathrm{rpm}$ \\
Max. tether tension & $\begin{array}{l}\text { Tested to } 17800 \mathrm{~N} \text { (4000 lbs.) of tension applied to } \\
\text { tether wrapped in a single layer on the winch } \\
\text { drum. }\end{array}$ \\
\hline
\end{tabular}

The path of the tether was selected to maximize the distance from the fairlead to the level-wind, and from the level-wind to the drum. The former would ensure lower side forces on the level-wind at the extreme positions near the flanges of the drum, while the latter would ensure easier laying of the tether on the drum. In addition, the tether exit point was chosen to be 
as close as possible to the centre of the winch to minimize undesirable moments on the robot. All surfaces that the tether contacted were designed to be smooth so as to not damage the tether. The only surface that the tether slid on - the exit angle sensor (Fig 12) - was lined with a low-friction material (polypropylene).

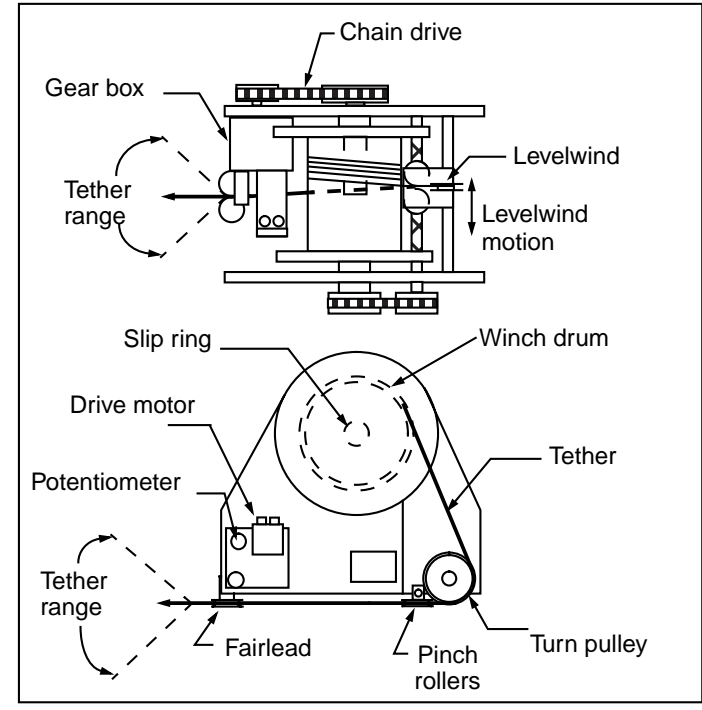

Fig. 11. Winch layout (Top view and side view)

\section{Tension sensing scheme}

Tension is sensed by the arrangement shown in Fig 12. The winch is mounted on four flexures, which have thin cross-sections and are compliant in the primary direction of pull. The flexures are however very stiff in the other two directions ensuring minimal flexure deflection due to tether tension components orthogonal to the primary direction of pull (horizontal direction in Fig 12).

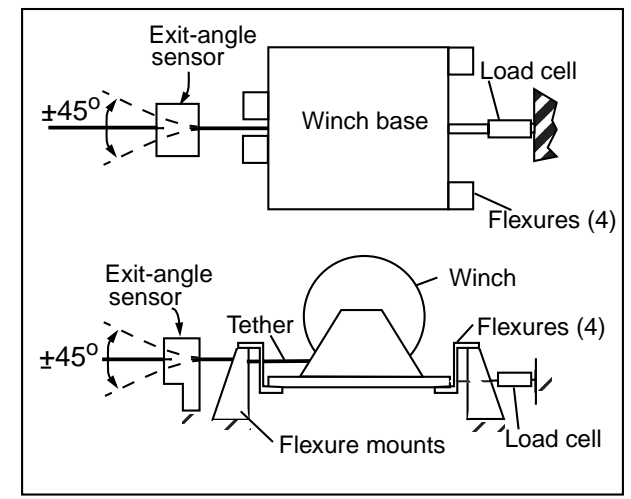

Fig. 12. Tension measurement setup (Top view and side view)

Thus the stiff load sensor mounted at the rear of the winch measures the component of tether tension in the primary direction of pull. The tether exit angle with respect to the robot is measured by an exit angle sensor mounted at the tether exit. The actual tension value can be computed using the exit angle and load cell reading. The exit angle and actual tension values help determine the robot's stability margin at all times.

The advantage of this tension sensing arrangement is that it does not involve any sliding parts. The motions are extremely small due to the stiff load sensor - of the order of $0.01 \mathrm{~mm}-$ and these motions are elastic deformations of the flexures. This is very suitable for use in corrosive environments, and cold environments where stiction can affect the performance of sliding surfaces.

\section{Summary and Conclusions}

To summarize, the important tethering system issues encountered and addressed during the Dante II program were:

- tether flexibility

- jacket friction and knifing

- tether management on the drum

- tether-robot force interaction.

The main contributions of this work are in the design, development and testing of a tethering system for a new and challenging application. The tether development pushed current perceptions of the ruggedness of composite cables. The severe testing program helped develop a successful solution to the tether design problem. We have attempted to compile the knowhow that goes into tethering system design by listing the issues of greatest concern when designing a tethering system for a mobile robot application. By describing the design process for the Dante II tethering system this paper begins the building of a framework for tethering system design which will help future tethered robot programs.

\section{References}

[1] Apostolopoulos, D., Bares, J. "Configuration of a Robust Rappelling Robot", IROS 1995, Pittsburgh, PA.

[2] Schempf, H., Bares, J., et al, Feb 1995. "BOA: Pipe Asbestos Insulation Removal Robot System”, American Nuclear Society 6th Topical Meeting on Robotic Systems, Monterey, CA.

[3] "Internal Pipe-Inspection System", 1992. Foster-Miller Product Literature, Waltham, MA.

[4] Schempf, H., May 1994. "Neptune: Above-Ground Storage Tank Inspection Robot System”. ICRA 94, San Francisco, $C A$.

[5] "Double Shell Tank Inspection System", Product literature, RedZone Robotics Inc., Pittsburgh, PA - 15222.

[6] “ROSIE", Product literature, RedZone Robotics Inc., Pittsburgh, $P A-15222$.

[7] "Composites — Engineered Materials Handbook", 1992. ASM International.

[8] Waloen, A. O., et. al., June 1992. "Fatigue, Internal Stresses and Deformations of Electrical Umbilicals. Analytical and Experimental Work". International Society of Offshore and Polar Engineers Conference, San Francisco, CA.

[9] "SAE Handbook", 1994. Published by Society of Automotive Engineers, Inc., Warrendale, PA. 